\title{
CROWD SOURCING OF PUBLIC TRANSPORT PROBLEMS
}

\author{
Sims, R.E., Ross, T., May, A. J. \\ Loughborough Design School, Loughborough University, UK
}

\begin{abstract}
Social sites on the World Wide Web allow increased sharing of ideas and problems. Such online networking includes the ability to report public transport problems and get support for campaigns to improve specific aspects of public transport. One site that offers such a facility provided access to its data on problems that were reported over a 13 month period. These were assessed and comparisons were made to see if those campaigns that got the most support were inherently different to the campaigns that received little support, and to investigate the types of problems that were reported online. Whilst definitive answers cannot be given, there are some suggestions that come out of the analysis and the overall impact on improving public transport accessibility and usability is discussed.
\end{abstract}

\section{Introduction}

The World Wide Web has grown exponentially since the first site was published in 1990. In 2011 it was estimated that $32.7 \%$ (that is 2.2 billion) of the global population were 'online' (Internet World Stats, 2012), having access to a computer at home/work/school or elsewhere that they could use to use the internet. Social networking sites such as Facebook, Twitter, etc. allow the interaction of people who might never have met face-to-face, but may share a common interest or aims. 'Crowd sourcing' (also known as user-generated content, community/social systems, or collective intelligence) is the use of data collected from multiple individuals, to develop shared outcomes (Doan et al, 2011). Crowd sourcing has been seen as a potential source of solutions to problems and a way of accessing ideas and innovations that might otherwise not be considered or discovered by standard design or innovation routes. FixMyTransport (www.fixmytransport.com) is one website that offers a platform for public transport users to report problems which are then automatically communicated to the relevant transport operator or local authority. 
FixMyTransport aims to make it easier for members of the public, and particularly those who are less confident about reporting problems, to send problem reports to the 'owner' of the issue. By enabling easier reporting of transport-related problems by a larger proportion of the population, it is expected that pressure can be brought to bear on transport operators to improve their services. In addition, the site will enable the public (and again particularly those less confident) to feel empowered to more actively engage in society by making their voice heard. Problems reported can include dirty seats, late trains, vandalised bus stops, poor signage etc. People are able to report issues as one-off 'problems', or they can post them as a 'campaign'. Campaigns can be supported by other people, who can opt to support the campaign and/or leave a message after the original posting.

The site can be accessed via computer or smart phone, enabling people to add problems as they occur, or to log on at a later point. The work detailed in this paper forms part of a larger project called Ideas in Transit (www.ideasintransit.org), with funding from the Engineering and Physical Sciences Research Council, the Technology Strategy Board and the Department for Transport. The project as a whole aimed to investigate many aspects of reducing car travel and promoting and supporting sustainable transport.

\section{Aims}

The aims of the work reported in this paper were to:

- $\quad$ Provide an overview of the campaigns that were reported on FixMyTransport in a 13 month period.

- To explore the characteristics of the campaigns that might influence the level of support it attracts (e.g. length of time since posted, transport mode, problem type, specific characteristics of the campaign post itself) to see if there was anything that could be said about the most successful campaigns when compared to campaigns with little support that might have influenced how successful they were (or not).

\section{Methods}

Access was provided to a database detailing all the campaigns and problems reported on FixMyTransport between $13^{\text {th }}$ July 2011 and $20^{\text {th }}$ August 2012. Simple counts were taken of how many campaigns had different numbers of supporters. It was found that there were 35 campaigns that had attracted 10 or more supporters. As 35 seemed a reasonable number of campaigns to investigate further within the time available, it was decided that these 35 would be designated the 'most supported' campaigns.

Two comparisons were then made between the 'most supported' campaigns and 35 campaigns that did not attract many or any supporters. Due to the large number of campaigns with 0 supporters or 1 supporter, the first comparison was made between 
35 of these campaigns that were 'matched' to the 'most supported' campaigns as closely as possible according to the length of time since the campaign was posted, and mode of transport. The second comparison was made with 35 campaigns with 0 or 1 supporter that matched, as closely as possible, the problem that was described in the 'most supported' campaigns. Overviews of both the 'most supported' campaigns and the campaigns with 0 or 1 supporter were also generated.

\section{Results}

It was found that, within the timeframe given, there were 1935 campaigns started in total. The number of supporters for campaigns ranged from 0 to 256 , but the majority of campaigns had 16 or fewer supporters, with 768 campaigns having only one supporter, and 576 having no supporters at the time of the analysis.

The types of problems that people started campaigns about varied widely. Table 1 shows the problems described in the campaigns with 10 or more supporters and the campaigns with 1 supporter. Percentages are used to take into account the different total sample sizes. There were 16 campaigns that only had 1 supporter where the problem described only occurred once: these are not in the table. In the campaigns with 10 or more supporters there were four that were only found once and no similar campaigns were found in the campaigns with 1 supporter. These were: bus stopping in advanced stop box for cycles at traffic lights, a ferry pier that was closing, a request to allow cycles on trams, and the location of the companion seat for accompanying a wheelchair user on trains. These are also not included in the table, to reduce the size of the table and make it easier to highlight the comparison and differences in percentages for the different types of problem in the campaigns with 1 supporter and the 'most supported' campaigns with 10 or more supporters.

In Table 1 'Timetable issues' include late running, slow running vehicles and vehicles leaving before the timetabled time. 'Routing' includes requests for services to different locations, unexpected changes of route on-journey, late changes of destination, and cancelled/missing services. 'Ticketing' includes problems with electronic payment, pricing issues, compensation requests and refund issues. 
Table 1: Percentages of each reported problem type for the 'most supported' campaigns and the campaigns with just 1 supporter (the totals might not be $100 \%$ due to some campaigns detailing multiple problems).

\begin{tabular}{|c|c|c|c|c|c|}
\hline Problem type & $\begin{array}{l}\% \text { of } \\
\text { sample } \\
\text { (campaigns } \\
\text { with } 1 \\
\text { supporter, } \\
\mathrm{n}=768 \text { ) }\end{array}$ & 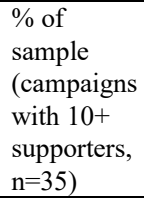 & Problem type & $\begin{array}{l}\% \text { of sample } \\
\text { (campaigns } \\
\text { with } 1 \\
\text { supporter, } \\
\mathrm{n}=768 \text { ) }\end{array}$ & $\begin{array}{l}\% \text { of } \\
\text { sample } \\
\text { (campaigns } \\
\text { with } 10+ \\
\text { supporters, } \\
\mathrm{n}=35 \text { ) }\end{array}$ \\
\hline $\begin{array}{l}\text { Poor driving/ } \\
\text { rude staff }\end{array}$ & 12.1 & 2.9 & $\begin{array}{l}\text { Failure of bus to } \\
\text { pick up/put down }\end{array}$ & 6.4 & \\
\hline $\begin{array}{l}\text { Over- } \\
\text { crowding }\end{array}$ & 11.2 & 2.9 & $\begin{array}{l}\text { Positioning of } \\
\text { bus stop }\end{array}$ & 2.2 & \\
\hline $\begin{array}{l}\text { Info unavailable/ } \\
\text { out of } \\
\text { date/requested }\end{array}$ & 10.3 & 2.8 & $\begin{array}{l}\text { Old vehicles } \\
\text { need replacing }\end{array}$ & 1.8 & \\
\hline Ticketing & 5.5 & 5.7 & $\begin{array}{l}\text { Heating on } \\
\text { vehicles }\end{array}$ & 1.7 & \\
\hline $\begin{array}{l}\text { Shelter } \\
\text { needed/ damaged }\end{array}$ & 3.8 & 2.9 & $\begin{array}{l}\text { Station/ stop } \\
\text { improvements } \\
\text { needed }\end{array}$ & 1.6 & \\
\hline $\begin{array}{l}\text { Electronic } \\
\text { display needed/ } \\
\text { inaccurate }\end{array}$ & 3.0 & 2.9 & $\begin{array}{l}\text { Broken down } \\
\text { vehicle }\end{array}$ & 1.3 & \\
\hline Access & 2 & 17.1 & $\begin{array}{l}\text { Stop/station } \\
\text { needs cleaning }\end{array}$ & 0.8 & \\
\hline $\begin{array}{l}\text { Ticket } \\
\text { machines } \\
\text { (lack of/ } \\
\text { problems }\end{array}$ & 1.3 & 2.9 & $\begin{array}{l}\text { Access to train } \\
\text { cycle storage }\end{array}$ & 0.7 & \\
\hline $\begin{array}{l}\text { Entrance/exit gate } \\
\text { issues }\end{array}$ & 1.1 & 5.7 & $\begin{array}{l}\text { Car park } \\
\text { issues }\end{array}$ & 0.7 & \\
\hline $\begin{array}{l}\text { Announcement } \\
\text { problems } \\
\text { (volume/number) }\end{array}$ & 1 & 2.9 & Vehicle noise & 0.7 & \\
\hline $\begin{array}{l}\text { Vehicles parked } \\
\text { in bus stop }\end{array}$ & 0.7 & 2.9 & $\begin{array}{l}\text { Internal vehicle } \\
\text { layout (including } \\
\text { luggage racks) }\end{array}$ & 0.7 & \\
\hline Signage problems & 0.7 & 2.9 & $\begin{array}{l}\text { Seating needed } \\
\text { at stop/station }\end{array}$ & 0.5 & \\
\hline $\begin{array}{l}\text { Cycle racks } \\
\text { needed }\end{array}$ & 0.4 & 11.4 & $\begin{array}{l}\text { Smoking on } \\
\text { bus/at bus stop }\end{array}$ & 0.5 & \\
\hline Toilet issues & 0.4 & 2.9 & $\begin{array}{l}\text { Leaking roof } \\
\text { of vehicle/ } \\
\text { waiting area }\end{array}$ & 0.4 & \\
\hline $\begin{array}{l}\text { Body part } \\
\text { trapped in } \\
\text { closing door }\end{array}$ & 0.4 & 2.9 & $\begin{array}{l}\text { Integration } \\
\text { between modes }\end{array}$ & 0.3 & \\
\hline $\begin{array}{l}\text { Wi-fi request/ } \\
\text { problem }\end{array}$ & 0.3 & 8.6 & $\begin{array}{l}\text { Seat } \\
\text { reservation issues }\end{array}$ & 0.3 & \\
\hline $\begin{array}{l}\text { Footbridge } \\
\text { needed/ problems }\end{array}$ & 0.3 & 2.8 & $\begin{array}{l}\text { Grit needed/ } \\
\text { slippery station }\end{array}$ & 0.3 & \\
\hline \multirow[t]{2}{*}{$\begin{array}{l}\text { Timetabling } \\
\text { issues }\end{array}$} & 23.9 & & $\begin{array}{l}\text { No refreshments } \\
\text { on-board }\end{array}$ & 0.3 & \\
\hline & 20.1 & & Station lighting & 0.3 & \\
\hline
\end{tabular}


Each campaign is identified by a Problem ID number. These are issued successively, so lower numbers are campaigns that were posted longer ago than higher numbers. For the 'most supported' campaigns, in terms of length of time since campaign was posted and the number of supporters, it was found that: 20 of the campaigns had Problem IDs less than 1000, 7 have Problem ID between 1500 and 3000, 3 have Problem ID greater than 3000 . This suggests that older campaigns are more likely to have gained more supporters. When looking at all campaigns with no supporters or only 1 supporter, however, there does not seem to be any relationship to length of time since the campaign was posted (Figure 1).

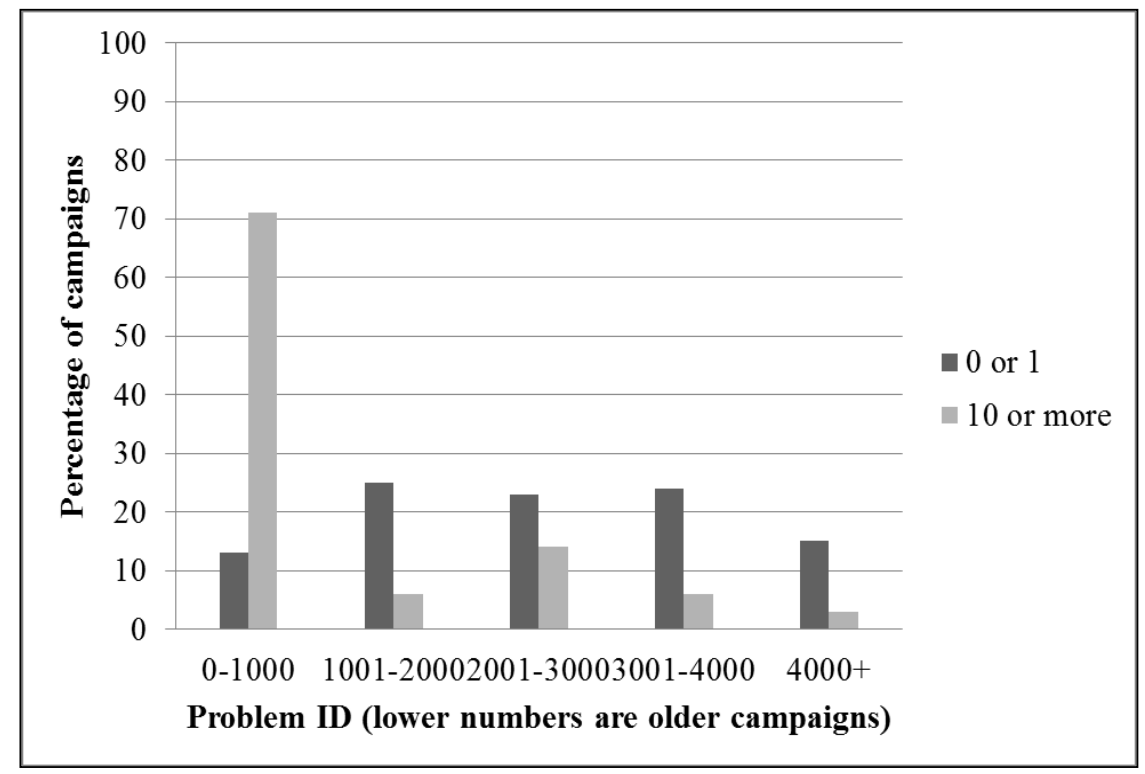

Figure 1: Graph showing Problem ID against percentage of campaigns with 0 or 1 supporter compared to Problem ID for campaigns with more than 10 supporters

In terms of mode of transport and the 'most supported' campaigns it was found that train was the most frequent mode of transport with 26 out of 35 campaigns. There were 4 for bus travel, 4 for tram/metro travel and 1 for ferry travel. When looking at all campaigns with 0 or 1 supporter, bus issues were the subject of 849 campaigns compared to 379 campaigns for train issues. 
Table 2: Characteristics of campaign posts for campaigns with $1+\& 1$ supporter, matched by mode of transport and Problem ID ( $n=35$ each)

\begin{tabular}{llll}
\hline \multirow{4}{*}{$\begin{array}{l}\text { Length of } \\
\text { post }\end{array}$} & Characteristics & $10+$ supporters & 1 supporter \\
\cline { 2 - 4 } & Short & 26 & 22 \\
\cline { 2 - 4 } & Medium & 2 & 11 \\
\cline { 2 - 4 } Type of event & one-off events/issues & 6 & 2 \\
\cline { 2 - 4 } & on-going issues & 29 & 28 \\
\cline { 2 - 4 } & mix one-off/on-going & 0 & 2 \\
\hline \multirow{3}{*}{ Writing style } & Offer solution(s) & 18 & 14 \\
\cline { 2 - 4 } & calm emotive & 10 & 14 \\
\cline { 2 - 4 } & not-calm emotive & 1 & 11 \\
\cline { 2 - 4 } & factual & 24 & 0 \\
\hline & Evidence of research & 5 & 0 \\
\hline & Mention consultation/petitions & 3 & 4 \\
\hline & Mention legislation & 6 & 1 \\
\hline & Use of exclamation marks & 0 & 0 \\
\hline
\end{tabular}

The 35 'most supported' campaigns were matched as closely as possible by mode of transport and then as closely as possible to Problem ID (so length of time since posting) to 35 campaigns with 1 supporter. It was expected that these matched campaigns would be similar in terms of length of time since posting on the site and mode of transport they concerned. A brief content analysis was conducted of the characteristics of the original campaign postings that were written on the site (Table 2).

When the 35 'most supported' campaigns were matched according to the type of problem being described in the campaign, it was not possible to find 35 matches in the campaigns with 1 supporter. In these instances the search was extended to include campaigns with 0 supporters. However, there were still some campaigns where no matching problem could be found. This resulted in 29 campaigns with 0 or 1 supporter being matched to 29 of the 35 'most supported' campaigns. Table 3 details the analysis of the content of the initial campaign messages posted for each of the 29 'most supported' campaigns and the matched campaigns with 0 or 1 supporter (matched by problem type). 
Table 3: Characteristics of campaign posts for 29 'most supported' campaigns and 29 campaigns with $0 / 1$ supporter, matched by problem type

\begin{tabular}{|c|c|c|c|}
\hline & Characteristics & 10+supporters & 0 or 1 supporter \\
\hline \multirow{3}{*}{$\begin{array}{l}\text { Length of } \\
\text { post }\end{array}$} & Short & 25 & 19 \\
\hline & Medium & 2 & 4 \\
\hline & Long & 2 & 6 \\
\hline \multirow{4}{*}{$\begin{array}{l}\text { Type of } \\
\text { event }\end{array}$} & one-off events/issues & 3 & 4 \\
\hline & on-going issues & 26 & 24 \\
\hline & mix one-off/on-going & 0 & 1 \\
\hline & Offer solution(s) & 18 & 13 \\
\hline \multirow{8}{*}{$\begin{array}{l}\text { Writing } \\
\text { style }\end{array}$} & calm emotive & 8 & 7 \\
\hline & not-calm emotive & 1 & 4 \\
\hline & factual & 20 & 18 \\
\hline & Evidence of research & 5 & 2 \\
\hline & Mention consultation/petitions & 3 & 0 \\
\hline & Mention legislation & 6 & 1 \\
\hline & Use of exclamation marks & 0 & 1 \\
\hline & Use of capital letters & 0 & 3 \\
\hline
\end{tabular}

\section{Discussion and conclusions}

It was found that the length of time since campaigns had been posted did not have an obvious impact in the low-supported campaigns, but support increased with time for the 'most supported' campaigns. There was a difference in prevalence of different modes of transport in the 'most supported' and low-supported campaigns. It is possible that this change arises from the fact that one train or train route will carry more people than a single bus or bus route, so a significant issue on a train/train route will impact on more people and garner more support. But overall there are far more buses and bus routes than trains and train routes, so more people could be impacted by individual problems when using buses than trains.

It is worth noting that the campaign with the most supporters had 256 supporters, with the next most supported campaign having only 41 supporters. The most supported campaign linked into an organisation with other social media links, and it is possible the campaign had been 'promoted' within the organisation, resulting in the increased support. In the comparison of 'most supported' campaigns and lowsupported campaigns matched on Problem ID and mode of transport it is seen that there were differences between the amount of not-calm emotive language ('ranting') used (with more in the low-supported campaigns), whilst there was not much difference between the numbers of campaigns offering solutions or being one-off 
versus on-going issues. In the comparison of 'most supported' campaigns with lowsupported campaigns matched on problem types, there was slightly more evidence of research/other petitions or consultation/legislation being mentioned, and less use of capital letters, exclamation marks and 'not calm' emotive language in the 'most supported' campaigns. There were also more medium/long campaign posts in the ' 0 or 1 supporter' matched group. In terms of the types of problems, the campaigns that gathered the most support were not necessarily the same as those problems which were found most frequently in the campaigns that only gained one supporter.

It is possible that short, to-the-point campaign posts, that avoid getting overly emotive and present the facts against a background of research/other support gain the most support. This has implications for people looking to start successful campaigns in the future, and for such websites in terms of the suggestions they make to contributors looking to make connections to other people and develop successful campaigns and networks with others with related interests. For campaigns that concern related issues but only have 1 supporter, if there was a way of joining these together to make a 'meta campaign', the number of instances of these problems being reported would result in them becoming part of the 'most supported' group of campaigns, with more than 10 supporters.

The work conducted here is only a very brief overview of the available data, but is an interesting first step into a relatively new area of exploration and within the context of the larger project to investigate ways to support and promote public transport usage, amongst other things. With increased time it would be possible to conduct a more rigorous qualitative analysis of all the data within the campaigns, and to draw more definitive conclusions regarding the content of more successful versus less successful campaigns. At the time of writing, in-depth questionnaires and interviews were being conducted with a sample of people who posted problems and campaigns on the site, to explore the 'type' of people who make complaints in this way, whether they had complained via alternative methods including talking to the driver/members of staff, and what impact they thought making the complaint online had. Initial results suggest that respondents generally had a positive response to raising their issues from the transport providers and found the experience of 'complaining' online to be positive. Crowd sourcing sites are keen to maximise the impact that their sites have and the benefit for the contributors to those sites, and for people working to improve public transport and uptake of public transport then any information that can help increase the effectiveness of crowd sourcing data and campaigns is of potential benefit.

\section{References}

Internet World Stats, 2012, www.internetworldstats.com (accessed September 2012) Doan, A., Ramakrishnan, R., \& Halevy, A.Y. 2011, Crowd sourcing systems of the World Wide Web. Communications of the ACM, 54 (4),_pp86-96. 